\title{
Ensayo en forma de tuits: sentidos y relatos de Martín- Barbero
}

\section{Omar Rincón}

Doctor; Universidad de los Andes, Bogotá, Colombia

orincon@uniandes.edu.co

\section{Resumen}

Este ensayo reflexiona sobre las frases más citadas del pensamiento de Jesús Martín-Barbero, cuyo tono aforístico puede adoptar "la figura narrativa" del tuit. Martín-Barbero no tiene cuenta de twitter, tampoco escribe tuits pero ha sido socializado con frases potentes que se pueden divulgar $y$ socializar en estilo twitter: pocas palabras, alto significado, contundencia emocional. Aquí la reflexión va sobre cuatro tuits: "hay que perder el objeto para ganar el proceso", "hay que pasar de los medios a las mediaciones", "no podemos ahorrarnos la cuestión de lo popular, ni de lo masivo, ni de lo popular masivo", "investigar la comunicación es ver con los otros". Se afirma que Martín-Barbero nos invita a pensar desde el Sur, y eso implica investigar e imaginar poniendo el cuerpo y ganando el relato.

\section{Palabras clave}

Martín-Barbero. Mediaciones. Popular. Comunicación. Sur.

Jesús Martín-Barbero es el pensador más pop \& cool que tenemos en el campo de los estudios culturales y la comunicación en América Latina. Lo es porque es el autor más citado en textos académicos, la figura que sigue emocionando a estudiantes y profesores y, por eso, tiene miles de seguidores. Lo atractivo de su pensamiento está en que logró producir diálogos y articulaciones entre la filosofía europea y los modos ensayísticos de pensar desde y con América Latina. Su virtud estuvo en atreverse a salir de "los tiempos muertos" del franquismo para meterse en la heterogeneidad cultural de los tiempos de América Latina. Todo mezclado y cocinado desde el lugar de enunciación latino al juntar lo popular con lo masivo sin perder el horizonte crítico del arte y las identidades. Esto de ser y sentir como 
latinoamericanos sigue pareciendo una herejía para un continente que sueña y desea con la cabeza de Estados Unidos y Europa.

Por esa razón, detrás de sus conceptos siempre hay una historia, ya que en América Latina para pensar, contamos; o sea, que antes que nazca un concepto, hay una historia de la realidad que la cristaliza. Por ejemplo, según narra él mismo, es a partir de historias que le llegaron las ideas, como el día en que Sarah Corona le contó que los "niños jugaban a la televisión", descubre que la clave no es jugar "con" sino jugar "a”; cuando en Cali los machos lloraban viendo "La ley del monte", lo llevaron a ver hacia y con la gente; cuando América Latina se hace moderna sin pasar por el libro y construye su "jodernidad" ${ }^{1}$, se da cuenta de los modos inéditos de ser modernos en oral-visualidades porque las imágenes y las oralidades "agarran más" que las escrituras; cuando investiga la televisión y describe que la gente goza más re-contando el capítulo que viéndolo porque en el re-contar meten su vida en el relato. Hay una mirada, hay unos conceptos, hay unas lecturas previas pero son las historias, el contar, lo que jala el pensar y crear pensamiento.

Este ensayo reflexiona sobre el pensamiento de Martín-Barbero que tiene como obra fundamental a De los medios a las mediaciones (MARTÍN-BARBERO, 1987) pero cuya enunciación ya estaba presente en su conferencia "Perder el objeto para ganar el proceso" de 1984 y publicada como texto en el 2012. En este contexto, se hace un viaje por sus frases más significativas cuyo tono aforístico puede adoptar la figura narrativa del tuit. Se afirma que Martín-Barbero nos invita a pensar desde el sur, y eso implica investigar e imaginar desde y con lo popular y asumiendo como inspiración lo narrativo más que lo conceptual.

De los medios a las mediaciones: comunicación, cultura y hegemonía apareció en 1987 (MARTÍN-BARBERO, 1987), su valor estaba en que había sido escrito desde el sur y su heterogeneidad cultural pero sin olvidar los sentidos del norte, el experimento fue juntar lo masivo-industrial con lo cultural-popular y la perspectiva de lo política en movimiento y en trasformación.

No sé, la pura verdad, no sé qué ha pasado con este libro. Yo lo hice y el trazó sus propios caminitos para caminar, se movió a su manera, se enredó con ciertas razones y ciertas visiones, y se ha trazado su camino propio. A mí lo que me importa es que está vivo y está vivo porque es un libro que ha movido, no solo la lectura de comunicadores sino también de gente de ciencias sociales. Y es que es un libro de ciencias sociales, no es un libro de

\footnotetext{
1 Una de las claves del pensar de Martín-Barbero es el juego de los conceptos, así para pensar esa modernidad fallida que vivimos en América Latina, él se atreve a llamarla oralmente "jodernidad”, algo así como la modernidad que se jodió, se estalló, se explotó... y también el modo de joda, humor, ironía, paradoja como América Latina asume y practica la modernidad.
} 
comunicación y medios. Escribí ese libro para incidir sobre las ciencias sociales metiendo una agenda de temas que me parecían importantes en política, sociedad, cultura. El libro ha recorrido una partecita del mundo y que todavía de alguna manera le queda una cierta energía para seguir creándome problemas (información verbal²).

La verdad es que este libro De los medios a las mediaciones sigue resistiendo lecturas, creando problemas y moviendo los tedios de la comunicación. Y es que para saber qué somos o desde dónde pensamos, hay que volver a él. Un volver a sorprenderse de su potencia teórica y ese mirar de otro modo. Con motivo de los 30 años de publicado y para la reunión de la International Association of Media and Communication Research (IAMCR) en Cartagena, Colombia, 2017, le solicité a muchos martinbarberianos que dijeran algo acerca de De los medios a las mediaciones. El maestro argento-mexicano García-Canclini nos dice que hoy sirve para "detectar diferencias y densidades entre lo que hoy se amontona en juegos de algoritmos"; el intelectual brasileño Renato Ortiz nos recuerda que sigue siendo "nueva tendencia intelectual entre nosotros"; el hiperdigital Carlos Scolari confirma que este libro es "a la reflexión teórica de la comunicación latinoamericana como Cien años de soledad es a su literatura"; la estudiosa del melodrama Nora Mazziotti recuerda la potencia de la categoría de las mediaciones ya que "enlaza prácticas, temporalidades, sensibilidades"; para el uruguayo Gabriel Kaplún este libro lleva al encuentro con "los saberes ignorados, ninguneados, obturados, intuidos o entrevistos en las prácticas cotidianas de la comunicación"; el español Manuel Chaparro reivindica "las narrativas propias, singulares, híbridas, mestizas de América Latina"; el ecuatoriano Pepe Laso nos habla del impacto ya que "nos cambió la forma no solo de mirar los medios sino el mundo que habitamos"; para la salvadoreña que trabaja en los Estados Unidos, Silvia López, representa diversas "maneras de heredar a Benjamin"; la pensadora anfibia Rossana Reguillo nos cuenta que este libro convirtió a Martín-Barbero en "una práctica significativa para una comunidad intelectual"; la salvadoreña Amparo Marroquín nos recuerda que este texto "todavía exige, sueña, rabia y ensaya respuestas"; el peruano Luis Peireano concluye que en este libro Martín-Barbero juntó sus tres vocaciones: "la de filósofo con la etnógrafo y la de poeta". El impacto cultural y académico de De los medios a las mediaciones está muy bien descrito por el aporte del argentino Claudio Tomas Lobo cuando dice que

\footnotetext{
${ }^{2}$ Entrevista sobre el concepto de Mediaciones a Jesús Martín-Babero, hecha por el autor de este texto, 22 de mayo del 2017.
} 
Supuso desde una dimensión ontológica, el corrimiento de una concepción de lo popular como negación, atraso y resabio de tradiciones estancas a concebirlo como una matriz capaz de generar nuevas subjetividades. Al interior del campo de los estudios de comunicación, significó además una ruptura epistemológica que nos permitió poner en crisis la afirmación desde la cual asumíamos a los medios como las grandes usinas de producción del sentido y entender que en los procesos de mediaciones del sentido es posible la emergencia de nuevas relaciones entre los colectivos 'nosotros' y los 'otros' por medio de procesos de repetición/naturalización y de resignificación/desplazamiento. Las mediaciones operarían a partir de la obra de Martín-Barbero como un espacio de umbralidad en las que las memorias de lo popular funcionarían como grandes dispositivos semióticos. Por último, la noción de mediaciones nos posibilitó comprender a la cultura como una trama de significaciones puestas a circular, flujos siempre aleatorios y contingentes en la que algunos sentidos sedimentan y otros operan como fuerzas centrífugas. (LOBO, 2017, doc. no paginado, grifos nuestros).

Dejando de lado el impacto de su obra, paso a su pensamiento y me concentro en el lado más leve, ese del saber socializado y canonizado vía "citaciones", "google" y "redes sociales"; esas frases que todos sabemos de memoria, aún sin saber de qué van. Y es que el pensamiento de Martín-Barbero se ha divulgado en formato twitter ${ }^{3}$ porque sus frases de sentido profundo caben en menos de 140 caracteres como eso de que "hay que perder el objeto para ganar el proceso", su famoso "hay que pasar de los medios a las mediaciones" y la más actual "Google sabe más de uno mismo que uno". En este ensayo intento explicar qué hay detrás de cada tuit-pensamiento martín-barberiano:

\section{\#hay que pasar de los medios a las mediaciones} (MARTÍN-BARBERO, 2012)

Esta es la categoría más citada en los estudios de la comunicación y la cultura, pero también la menos saboreada/comprendida/intervenida. Y es que a pesar de las más de 300 páginas, Martín-Barbero nunca define qué es la categoría Mediaciones. En principio significa abandonar "el mediacentrismo", el norteamericanismo y los dualismos morales de derecha e izquierda. Este llamado sigue siendo útil en el siglo XXI, ya que seguimos creyendo que el sol sale por los Estados Unidos, los medios diseñan omnipotentemente la vida social y siempre hay buenos y malos. Esta apuesta por ir a los grises es necesaria en nuestro pensar de la comunicación y la cultura ya que tanto la izquierda en nombre del proletariado y Marx

\footnotetext{
${ }^{3}$ Jesús Martín-Barbero no tiene cuenta de twitter, tampoco escribe tuits. Aquí nos referimos a pensamiento twitter como "figura narrativa" que da cuenta que un autor tiene frases potentes que se pueden divulgar y socializar en estilo twitter: pocas palabras, alto significado, contundencia emocional. La construcción puede que no corresponda exactamente a una cita citable sino a una comprensión que he hecho sobre las lecturas de y las conversaciones con Martín-Barbero.
} 
como la derecha en nombre de dios, tradición y propiedad privada reparten el mundo en dos bandos de virtuosos y pecadores. Y hay que ir más allá, siempre dudar de las morales maniqueas.

El llamado era, y es, a estudiar, comprender, criticar y transformar los medios porque son máquinas hegemónicas que más que informar y entretener trabajan como actores políticos que militan en una sociedad financiera, monoteísta de los empresarios privados y en el reino del dios-mercado; pero no quedarse ahí en la crítica, sino ir más allá de los medios a la vida de la gente para comprender los procesos, prácticas y experiencias de compartir y producir sentido desde y en el territorio, a imaginar y subvertir desde abajo, a rebuscar el relato, los cuerpos y el humor que es el capital cultural de lo popular.

Las mediaciones es una categoría para pensar en el in-between, en la ambigüedad, en el articular. No es una categoría higiénica ni neutra sino todo lo contrario: llena de lo político que se revela y lucha por ser de otra manera; contradictoria como es lo popular y lo masivo, ya que da cuenta de prácticas y procesos de resistencia y sumisión en simultáneo; una categoría que permite darnos cuenta de la heterogeneidad de temporalidades y culturas que habitamos: esas largas y densas de las identidades ancestrales, esas cortas y efímeras del mercado, esas lentas de caminar la palabra, esas inéditas de los flujos digitales.

Bueno y ¿qué son las mediaciones? No son eso que el maestro español Manuel Martín Serrano (1977) llamó "La mediación social” ya que este autor propone una teoría crítica sobre el poder mediático en la constitución de los sentidos públicos y, por eso, analiza cuáles son y cómo funcionan los mecanismos de control de las visiones del mundo que hacen los medios e impactan en la sociedad. Tampoco es lo que el maestro mexicano Guillermo Orozco (2002) llama mediaciones; Orozco define como mediaciones a esos procesos estructurantes y operadores de apropiación, lectura y sentidos que se dan en las audiencias; mediaciones que pueden ser subjetivas, situacionales, de vínculo, contexto, cognición o de saber mediático. Orozco al contrario de Martin Serrano no busca el poder de los medios sino que se interesa en lo que sucede en los procesos y prácticas de construir sentido y placeres por las audiencias.

Si uno se atreve a definirla al modo Martín-Barbero, uno podría encontrar que las mediaciones son algo que está hecho de flujos de lo cultural (popular), lo industrial moderno (mercado) y lo político (luchas por el poder y los movimientos sociales). La clave está en el concepto de "articulación" ya que no es un asunto de impactos o efectos (MARTín SERRANO, 1977) ni de intermediaciones para la interpretación (OROZCO, 2002) sino 
"articulaciones" entre los modos de lo popular, la industria cultural de lo masivo y los movimientos y procesos de lo político. Así, usar la categoría "mediaciones" en la referencia martin-barberiana da cuenta descriptiva y analíticamente de esta articulación entre lo popular-lo masivo-lo político. Él nunca lo afirma pero se puede intuir que es este triple vínculo el que hace que esta categoría de cuenta de manera más robusta y crítica de las complejas formas de significar y sentir que viene desde abajo, se convierten en industriales para jugar en el campo de lo político.

Lo siguiente es asumir que esta articulación debe ser puesta en práctica de manera crítica y trasformadora: no basta con describir, hay que intervenir las prácticas, procesos y experiencias comunicativas. Por eso lo que significa "pasar de los medios a las mediaciones" (MARTÍN-BARBERO, 1987) es hacer "investigables los procesos de constitución de lo masivo más allá de la degradación cultural que indicaban los ilustrados y la izquierda" (MARTÍN-BARBERO, 2012), “cambiar el lugar de las preguntas” (MARTÍN-BARBERO, 1997), "mirar los medios con la gente" (MARTÍN-BARBERO; CORONA, 2018) y comprender los placeres y práctica que nos dan los medios.

Como categoría, las mediaciones proponen dar cuenta de tensiones y opacidades que habita la comunicación en el horizonte de las culturas y lo político. La tensión entre los formatos industriales diseñados técnicamente que se enfrentan con las matrices culturales o donde residen las memorias, las identidades y las prácticas del goce. Esta tensión explica por qué el mercado y sus técnicos culturales no logran "dominar" y "homogenizar" la sociedad; ya que, si no reconocen los modos culturales de cada comunidad, el formato o producto fracasa. Por eso el productor cultural o el comunicador encuentra la "comunicabilidad" cuando a su conocimiento, de lo industrial y técnico, le agrega saber de territorio y cultura.

La otra tensión es entre las lógicas de producción y los modos cómo asistimos y gozamos los productos culturales y comunicativos. Las lógicas de producción dan cuenta de esos saberes de modelos de gestión y ejecución que llevan a crear un producto cultural o una obra comunicativa, también se debe conocer las políticas públicas respecto a la soberanía comunicativa y la libertad de expresión. Las lógicas de disfrute reconocen los modos de recepción, consumo, placer, usos e interpelación que hace la gente con lo que ve, lee, escucha y se conecta; esos modos como programamos nuestros placeres. En esta tensión para ganar comunicabilidad hay que saber de lo que sucede en las comunidades de audiencia: escucharlas, estudiarlas, comprenderlas, encontrarlas; por eso, conocer/saborear 
las audiencias o prosumidores, que llaman hoy, es un requisito para ganar vínculo entre los productos culturales y los ciudadanos.

\section{\#hay que perder el objeto para ganar el proceso} (MARTÍN-BARBERO, 20124)

La comunicación buscaba ser reconocida como ciencia y buscada desesperadamente "su objeto de investigación". Esto era en los años 80 del siglo pasado. Ese objeto era elusivo: si le hacíamos caso a la semiología debería ser "el mensaje" o "contenido" de los medios, lo que se debería pensar; pero si nos íbamos con los teóricos de la comunicación, el objeto eran "los medios" o "la información". Corrían los años 80 cuando el espacio de la comunicación se volvió un lugar estratégico para pensar algunas de las contradicciones del desarrollo, la política y la cultura en América Latina. Entonces, Martín-Barbero propone dejar "la obsesión por el objeto propio" (MARTÍN-BARBERO, 1987; MARTÍN-BARBERO, 2012) para empezar a estudiar los procesos como se hacía la comunicación. Si se estudia cómo se hace la comunicación, se comprende que es desde la cultura; eso significa pasar de estudiar a los medios para pasar a estudiar los procesos culturales de producción, circulación y consumo de los mensajes. Su propuesta implicaba partir de la realidad para luego si llegar a la teoría, asumir los procesos de comunicación en su opacidad para desde ahí construir los sentidos de la misma.

Estábamos convencidos de que quien nos decía lo que era comunicación, lo que era relevante en comunicación, era la teoría. Durante mucho tiempo hemos estado convencidos de que el problema gravísimo era no tener una teoría que nos dijera con claridad qué es comunicación. 0 a nivel de la especificidad profesional: ¿qué diablos hace un comunicador? Yo diría que, aunque parezca paradójico, durante estos últimos años, tuvimos que perder la obsesión por el objeto propio, tuvimos que perder la obsesión positivista por acortar la especificidad de nuestro campo, para que pudiéramos empezar a escuchar en serio las voces que nos llegan de los procesos reales en los que la comunicación se produce en América Latina. Y voy seguir con la paradoja: hemos tenido que perder la seguridad que nos daba la semiología o la psicología, o la teoría de la información, para que nos encontráramos a la intemperie, sin dogmas, sin falsas seguridades, y solo entonces empezáramos a comprender que lo que es comunicación en América Latina no nos lo puede decir ni la semiología ni la teoría de la información, no nos lo puede decir sino la puesta a la escucha de cómo vive la gente la comunicación, de cómo se comunica la gente (MARTíNBARBERO, 2012, p. 78).

\footnotetext{
${ }^{4}$ Este texto de una conferencia dictada en la Facultad de Comunicación Social de la Universidad Javeriana, Bogotá, el 2 de marzo de 1984 bajo el título De la comunicación a la cultura. Perder el "objeto" para ganar el proceso. Este texto se publicó en la revista Signo y Pensamiento en el año 1984 (v. 3, n. 5, p. 17-24). Todas las referencias a Martín-Barbero (2012) dan cuenta de la fecha de publicación del texto que originalmente es de 1984.
} 
Más que mirar solo a las tecnologías y a los medios, el asunto era comprender lo que hace la gente con los medios en su vida cotidiana: pasar de la comunicación como dispositivo de información a la cultura como lugar de la diversidad y heterogeneidad de identidades de América Latina. Y también enuncia, en ese lejano 1984, su apuesta por los "mapas nocturnos" para investigar a la intemperie, en donde sentir e intuir es tan importante como saber.

\section{\#no podemos ahorrarnos la cuestión de lo popular, ni de lo masivo, ni de lo popular masivo (MARTÍN-BARBERO, 1981)}

Lo popular expresa una "clase", y por tanto, un pecado cultural para la civilización escritural e ilustrada; ese popular anarquista incoherente paradójico es comprendido por Martín-Barbero como clave para comprender la comunicación en perspectiva cultural y política. En 1984 ya decía que lo popular era desde donde se comprende la comunicación, "el lugar desde el cual pensar el aquí y el ahora".

Lo popular "el lugar" desde el cual se hace posible pensar hoy tanto los procesos de comunicación que desbordan lo nacional por arriba, es decir, los procesos macro que involucran la puesta en funcionamiento de los satélites y las tecnologías de informática; como los procesos de comunicación que desbordan lo nacional por abajo, desde la multiplicidad de las formas de protesta regional, local, ligadas a existencia negada pero viva de la heterogeneidad cultural. Hoy lo popular en América latina nombra algo muy especial, que realmente no tiene el mismo sentido ni en Europa, ni en los otros continentes. Decir en EE.UU. o en Europa "Cultura popular" es decir una de dos cosas: o cultura masiva, o cultura de museos (MARTÍN-BARBERO, 2012, p. 81).

Pero no cualquier popular, no el del folclore o el que se queda en lo exótico sino que se atrevió a juntarlo con lo masivo, con ese pecado de lo industrial y el mercado. Y lo hizo para develar como "la cultura de masas recupera matrices, modos de percepción de lo popular" pero lo hace para hacer negocio y "desactivarlo, deformarlos, despolitizarlo" para así "neutralizarlos". No solo devela y crítica la máquina mediática, también recupera el potencial de las clases populares ya que si ellas invierten "deseo" en esos medios y extraen placeres es porque para ellas "eso" tiene muchos sentidos y goces. Por eso lo popularmasivo "se convierte en un gran espacio para estudiar, para investigar esas matrices deformadas de lo popular a través de las cuales las masas siguen < dejándose atrapar>", pero también para encontrar "los usos populares de lo masivo", esos juegos de complicidad 
y resistencia que se reconocen en lo que hace la gente con lo masivo. (MARTÍN-BARBERO, 2012, p. 83)

Lo popular es, entonces, una experiencia de re-encantamiento del mundo de la vida que reivindica los placeres cotidianos como expresión anarquista que se hace delicia corporal, goce público, disfrute colectivo, expresión narrativa del existir; como experiencia de gestión de "lo festivo que está siendo reinventado, en su más fuerte sentido ritual, el de tiempo denso de lo comunitario" (MARTÍN BARBERO, 2008, p. 14). Por eso, lo popular es "memoria de una experiencia sin discurso que se deja decir solo en el relato" (MARTínBARBERO; MUÑOZ, 1992, p. 23): lo popular existe en el relato, por eso quien narra no está muerto.

\#hay que cambiar la mirada y mirar hacia los que gozan con los medios porque ahí es donde se localiza lo que da sentido (MARTÍN-BARBERO; CORONA, 2018)

\#investigar la comunicación es "ver con los otros" (MARTÍN-BARBERO; CORONA, 2018)

De los medios a las mediaciones nos obligó a cambiar el lugar de las preguntas y las miradas para pasar a "mirar desde el otro lado", con y desde la gente. Y este mirar "con y desde los otros" hace que pensemos de otros modos; nos lleva a estudiar los juegos de los re-conocimientos más que de los "conocimientos", en donde lo que importa no es el qué sino el cómo, el narrar, el tono, el estilo, la política. Esos modos del relato y esos rituales inscritos en la identidad. Si vamos a mirar ese otro modo de ver, ese otro modo de narrar y significar, ese otro modo de vivir y desear, esos otros placeres comenzamos a comprender lo que pasa de político y social por la comunicación localizada en procesos culturales. Ese mirar con y desde los otros nos lleva a salir de la producción, el mensaje y las audiencias para ingresar en los modos densos del constituir e instituir de lo político y lo cultural.

Me quedo con estas cuatro ideas claves de la obra de Jesús Martín-Barbero que creo dan cuenta de lo más potente y perdurable en su pensamiento y propuesta analítica: mirar con los otros y en mapa nocturno; localizar la enunciación en las culturas populares y sus modos de producir placeres y sentido; enfocarse en los procesos y prácticas más que en los objetos y medios; pensar e investigar las mediaciones como articulación de lo político, lo 
popular y lo industrial. Pero hay muchos más tuits que nos pueden poner a pensar. Por ejemplo:

Rescata el narrar como modo de pensar de las culturas populares y de lo latinoamericano, el narrar como producción de conocimiento desde la experiencia de vida.

\#investigo lo que me genera esperanza (MARTÍN-BARBERO, información verbal ${ }^{5}$ )

Nos recuerda que hay que estudiar y pensar lo que nos brinde futuro, aquello que provea de sentido en perspectiva de la transformación social, en empatía con la sociedad y sus necesidades políticas.

\#no he venido a buscar los efectos ni las audiencias sino los reconocimientos (BONILLA et al., 2012)

Nos aboca a otros modos de entender las relaciones entre cultura y medios ya que pone el énfasis en los procesos de identificación cultural más que en la "transmisión" de conocimientos. Esto explica el fracaso de los gobiernos de derecha e izquierda, unos por valores religiosos y de clase y otros por propaganda política, al "inyectar" conocimientos a través de la comunicación sin pasar por el reconocimiento de los ciudadanos.

\section{\#mientras la televisión comercial se hace para el consumidor, la televisión pública se diseña y realiza para el ciudadano} (MARTÍN-BARBERO; RINCÓN, 2005)

Y es que los medios privados siempre buscan al consumidor: el que compra su producto informativo o de ficción para que, además, compre otros productos, mientras que los medios públicos deben convocar al ciudadano con sus saberes, estéticas y derechos; es más, los medios públicos deben ser protagonizados por los ciudadanos: ellos deben tomarse las pantallas.

\footnotetext{
${ }^{5}$ Conversaciones del autor con el profesor Martín-Barbero, en el año 2012, en su casa en Bogotá, como parte del trabajo para planificar un texto sobre Manifiestos: incómodos, desobedientes, mutantes (MARTÍN-BARBERO; RINCÓN, 2014).
} 


\section{\#si la educación no se hace cargo de los cambios culturales que pasan hoy decisivamente por los procesos de comunicación e información no es posible formar ciudadanos.} (MARTÍN-BARBERO, 2003)

La sociedad está de acuerdo que la Educación es la clave de la transformación social y política, pero la educación se ha quedado en conservar el saber, en cosificar el conocimiento, en moralizar los consumos culturales del estudiante. Esto ha llevado a que la educación no se haga cargo de las tecnologías o los medios más que para domesticarlos y naturalizarlos como "transmisores" de contenido, cuando tecnologías y medios traen mundos nuevos, consumos culturales diferentes, saberes distintos que deben ser incluidos como parte de la formación orgánica del ciudadano.

\section{\#la comunicación debe proponer experiencias de re-} encantamiento identitario (MARTÍN-BARBERO, 1987)

El poder de la comunicación y la cultura está en sus modos de jugar, ritualizar, celebrar la vida desde lo emocional y en colectivo. Y ante la pérdida de misterio en la vida por la razón moderna, las prácticas de comunicación establecen escenarios novedosos para y desde la narración estética popular y pop, poner en juego las identidades olvidadas, ninguneadas, excluidas como lo están haciendo las culturas ancestrales indígenas y afros, las sensibilidades LGTBI y feministas y las fes evangélicas.

\section{\# el internet es una revolución no de la distribución (Gutemberg), sino de la escritura, y en internet estamos escribiendo de manera oralvisual} (MARTÍN-BARBERO, información verbal ${ }^{6}$ )

Por lo tanto, la revolución no es la cantidad enorme de información que se distribuye; además, una información sin centro, dispersa y fragmentaria que adquiere sentido solo en sus usos o en la edición que hagamos cada uno de nosotros como curadores, djs o programadores. Lo novedoso es que Internet y las redes digitales son otras formas de escribir, cada vez menos de letra y más orales y visuales, de links/conexiones, de flujos por imágenes, de emoticones y memes, de audios y fotos, de escritura entre todos.

Y todo adquiere saber orgánico cuando Martín-Barbero tuitea:

${ }^{6}$ Conversaciones del autor con Martín Barbero, entrevista sobre los modos de pensar lo digital, Bogotá, mayo $26,2016$. 


\section{\#todo comunicador debe hacer tres cosas: pensar con la propia cabeza... tener qué decir... y ganarse la escucha (MARTÍN-BARBERO, información verbal7)}

Una fórmula muy simple pero potente. Para comunicar tenemos que tener cabeza propia que nos asigne una mirada al mundo, unos recursos para narrar con voz propia, unos saberes para poder contar con potencia. Tener qué decir porque hay mucha información en las redes y medios, mucho video en youtube, millones de post en facebook, incontinencia de tuits en twitter, miles de canales de televisión, radios por todas partes,pero no dicen nada. No tienen nada que contar por eso se dedican al efecto tecnológico, a mover la cámara o al insulto escandaloso. Cuando no se tiene nada que decir se recurre al tono sensacionalista y agresivo, y en eso vamos mal: mucha comunicación, poco que conversar. Ganarse la escucha en este mar de informaciones y ofertas de entretenimiento es muy difícil, no es fácil conectarse con los ciudadanos y la sociedad, para eso el recurso del comunicador es narrar muy bien usando las estructuras dramatúrgicas que tengan sentido en las comunidades, con la experimentación de formatos desde el territorio y las identidades, y en agendas, tonos y estéticas que provean reconocimiento a los ciudadanos.

El pensamiento de Martín-Barbero y de su libro De los medios a las mediaciones nos sirve y mucho a los que pensamos la cultura, la comunicación y la política porque nos sigue llevando a "pensar distinto": desde y con la gente, en lo narrativo y lo estético, en lo sensible y lo político, en lo popular y latinoamericano. Y eso significa "pensar desde abajo, por la izquierda y con la tierra" como dice Arturo Escobar (2016). Martín-Barbero nos invita a pensar desde el Sur, y eso implica pensar, investigar, imaginar poniendo el cuerpo y ganando el relato. Poniendo el cuerpo implica practicar lo intercultural, asumir que en América Latina se significa desde la experiencia, desde el vivir, desde y en los rituales de la identidad, desde el cuerpo que baila, juega, ríe y cree. Y esta experiencia del vivir es la que deviene historia, cuento, relato desde dónde y en dónde nos "comprendemos" como sujetos, colectivos y culturas que habitamos, encarnamos y cristalizamos los conceptos en experiencias de vida.

${ }^{7}$ Conversaciones del autor con Martín Barbero, entrevista sobre el oficio de la comunicación, Bogotá, noviembre 22, 2010. 


\section{Referencias}

BONILLA, Jorge Iván et al. De las audiencias contemplativas a los productores conectados. Cali: Universidad Javeriana, 2012.

ESCOBAR, Arturo. Desde abajo, por la izquierda y con la tierra. El País, [S.l.], 17 ene. 2016.

LOBO, Claudio Tomás. 30 años. Dos meios ás mediacoes. Jesús Martín-Barbero. Cartagena: IAMCR, 2017.

MARTÍN-BARBERO, Jesús. Prácticas de la comunicación en la cultura popular: mercados, plazas, cementerios y espacios de ocio. IN: SIMPSON GRINBERG, Máximo. Comunicación alternativa y cambio social. México: UNAM, 1981.

MARTÍN-BARBERO, Jesús. De los medios a las mediaciones. Barcelona: Gustavo Gili, 1987.

MARTÍN-BARBERO, Jesús; MUÑOZ, Sonia. Televisión y melodrama. Bogotá: Tercer Mundo editores, 1992.

MARTÍN-BARBERO, Jesús. Los mapas diurnos y nocturnos. Nómadas, Bogotá, n. 7, p. 145169, 1997.

MARTÍN-BARBERO, Jesús. La comunicación desde la educación. Buenos Aires: Norma, 2003.

MARTÍN-BARBERO, Jesús. Lo sagrado y lo global. Des.localizaciones de los sagrado y reencantamiento del mundo. In: SEMINARIO INTERNACIONAL LO SAGRADO Y LOS MEDIOS DE COMUNICACIÓN, 2008, Valencia. Anais... Valencia, 2008.

MARTÍN-BARBERO, Jesús. De la comunicación a la cultura: perder el "objeto" para ganar el proceso. Signo y Pensamiento, Bogotá, v. 30, n. 60, p. 76-84, 2012. Republicacción del texto original de 1984 (revista Signo y Pensamiento, v. 3, n. 5, p. 17-24, 1984) de la conferencia dictada en la Facultad de Comunicación Social de la Universidad Javeriana, Bogotá, el 2 de marzo de 1984.

MARTÍN-BARBERO, Jesús; CORONA, Sarah. Ver con los otros: Comunicación intercultural. México: Fondo de Cultura, 2018.

MARTÍN-BARBERO, Jesús; RINCÓN, Omar (Org.). Manifiestos: incómodos, desobedientes, mutantes. Bogotá: Fundación Friedrich Ebert, 2014.

MARTÍN-BARBERO, Jesús; RINCÓN, Omar. Televisión pública: del consumidor al ciudadano. Buenos Aires: La Crujía, 2005.

MARTÍN SERRANO, Manuel. La mediación social. Madrid: Akal, 1977.

OROZCO, Guillermo. Recepción y mediaciones. Buenos Aires: Norma, 2002. 


\title{
Essay in the form of tweets: meanings and stories of Martín-Barbero
}

\begin{abstract}
In this essay, we reflect on the most cited sentences of Jesús Martín-Barbero, whose aphoristic style can adopt "the narrative figure" of a tweet. Martín-Barbero does not have a Twitter account, nor does he write tweets, but he has been socialized with powerful sentences that can be spread and socialized in Twitter style: few words, huge meaning and emotional impact. The reflection is about four tweets: "you have to lose the object to win the process"; "you have to go from the media to the mediations"; "we can not save ourselves from the question of the popular, neither of the massive, nor of the massive popular"; and "researching communication means seeing with others" It is said that Martín-Barbero invites us to think from the South, and that implies investigating and imagining by putting yourself in the position and getting our own stories.
\end{abstract}

\section{Keywords}

Martín-Barbero. Mediations. Popular. Communication. South.

\section{Ensaio em forma de tweets: sentidos e relatos de Martín-Barbero}

\section{Resumo}

Esse ensaio reflete sobre as frases mais citadas de Jesús MartínBarbero, cujo tom aforístico pode adotar a "figura narrativa" de um tweet. Martín-Barbero não tem uma conta no Twitter, nem escreve tuites, mas ele foi socializado com frases fortes que podem ser difundidas e socializadas no estilo do Twitter: poucas palavras, com grandes significados e com impacto emocional. Reflete sobre quatro tuites: "você tem de perder o objeto para ganhar o processo"; você tem que ir dos meios às mediações; "não podemos nos salvar da questão do popular, nem do massivo, nem do popular massivo"; e "investigar a comunicação é ver com os outros". Afirma-se que Martín-Barbero nos convida a pensar a partir do Sul, e isso implica investigar e imaginar colocando o corpo e ganhando a narrativa.

\section{Palavras-chave}

Martín-Barbero. Mediações. Popular. Comunicação. Sul.

Recebido em 18/03/2018

Aceito em 16/05/2018 